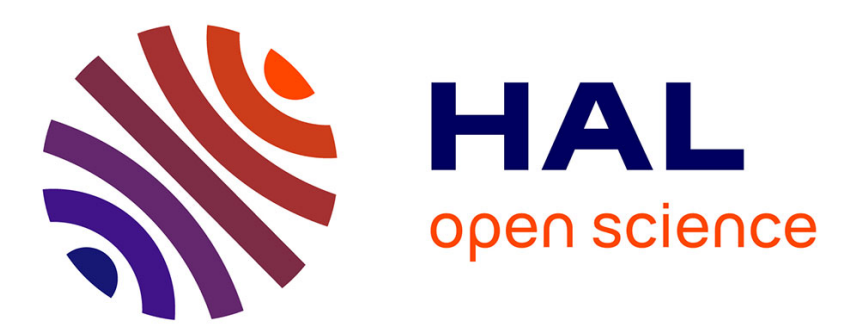

\title{
Limiting discrepancies when substituting Mohr-Coulomb with fast computation smooth criteria: application to ballast layers
}

Thibault Badinier, Siegfried Maiolino

\section{- To cite this version:}

Thibault Badinier, Siegfried Maiolino. Limiting discrepancies when substituting Mohr-Coulomb with fast computation smooth criteria: application to ballast layers. International Journal of Railway Technology, 2018, 7 (2), pp.41-66. 10.4203/ijrt.7.2.3 . hal-03159168

\section{HAL Id: hal-03159168 \\ https://hal.science/hal-03159168}

Submitted on 31 May 2021

HAL is a multi-disciplinary open access archive for the deposit and dissemination of scientific research documents, whether they are published or not. The documents may come from teaching and research institutions in France or abroad, or from public or private research centers.
L'archive ouverte pluridisciplinaire HAL, est destinée au dépôt et à la diffusion de documents scientifiques de niveau recherche, publiés ou non, émanant des établissements d'enseignement et de recherche français ou étrangers, des laboratoires publics ou privés. 


\title{
Limiting Discrepancies in Substitution of Mohr-Coulomb with Fast Computation Smooth Criteria: Application to Ballast Layer
}

\author{
T. Badinier ${ }^{1,2}$; S. Maïolino ${ }^{3}$ \\ ${ }^{1}$ GERS-SRO, Univ Gustave Eiffel, IFSTTAR, F-77447 Marne-la-Vallée, France \\ ${ }^{2}$ IMSIA, UMR 9219, Institut de Sciences de la Mécanique et Applications Indus- \\ trielles, ENSTA ParisTech, Palaiseau, France \\ ${ }^{3}$ Département Laboratoire de Lyon, Cerema Centre-Est, Bron, France
}

This document is a proof version, final version published by International Journal of Railway Technology in 2018 is available at doi : 10.4203 i j rt. 7.2 .3

\begin{abstract}
While the Mohr-Coulomb criterion is widely used in geotechnics, the DruckerPrager is common in Finite Element Methods software. Its circular shape is really a great advantage from a numerical point of view, even it is a drawback from a physical point of view.

In contrast, the Matsuoka-Nakai criterion seems to best fit material behaviour, particularly with regard to true triaxial tests. More over its smooth shape is also closer to the Mohr-Coulomb shape than that of the Drucker-Prager.

However, the circular shape of Drucker-Prager allows rapid and straightforward computations of plastic strain, due to the use of the radial return closed form. In contrast, the closest point projection method used to compute plastic strain for other criteria is more complex to implement and need more computation time.

Maiolino and Luong have shown that using the Drucker-Prager criterion as a substitution for a Mohr-Coulomb criterion induces great discrepancies of the friction angle. But in previous work we have already shown that the choice of an alternative criterion should not be made without considering the particularities of load and structure. We have also already demonstrated that we obtain acceptable results on our models when we used an appropriate Drucker-Prager Criterion.

In this paper, we analyse the discrepancy induced by the use of alternative criteria to the Mohr-Coulomb in order to choose a criterion which provides both faster analysis and a good approximation of the stress strain state in ballast.
\end{abstract}

Keywords: railway, ballast, geomaterials, criterion, Mohr-Coulomb, Drucker-Prager, Matsuoka-Nakai, numeric modelling, finites elements. 


\section{Introduction}

Today numerical models are widely used to predict the behaviour of structures under a specific load. Finite element analysis is one of the most commonly used modelling methods in engineering studies.

Studying railways, the ballast materials is generally modelled with elastic-plastic behaviour models commonly used in geotechnicals studies. The most common failure criterion encountered in geotechnical engineering is the Mohr-coulomb criterion. Its parameters are meaningful for engineers and are easy to deduce from tests. However, this criterion is less straightforward to implement due to the presence of corners in the yield surface shape. In opposition, the Drucker-Prager criterion and the MatsuokaNakai criterion has smooth shape and are also commonly used in geotechinicals studies. Both criteria have advantages and drawback compared to the Mohr-Coulomb Criterion. Easier to implement, faster to computes, over or under estimated resistance of the materials, better fitting to experimental results, are pros and cons arguments for the Mohr-Coulomb criteria substitution by one of these two.

In order to accelerate computation, and keep accurate representation of the materials behaviour we wanted to use and wisely chosen alternative criterion instead of Mohr-Coulomb. Some more complex models used to describe ballast behaviour such has Suiker'[1] and Einav'[2, 3, 4] models are based on Drucker-Prager like criterion. A wisely choose Drucker-Prager criterion could help to better fit those models.

In this paper we define a method to choose the best alternative criterion to the Mohr-Coulomb for a particular study. Maiolino and Luong [5] have proposed a way of measuring the discrepancies between criteria. Based on this measurement and on some models, we have exposed an innovative choosing process [6] investigating a way of measuring the discrepancies induced using an alternative criterion. In this paper we extend previous work by illustrating the process with railways ballast modelling. The behaviour of two railways structures are computed using each of Mohr-Coulomb, Matsuoka-Nakai and Drucker-Prager criteria. Then results are compared in order to choose alternative criterion for a specific study. Finally, parametrized Drucker-Prager criteria are introduced to improve and optimise the alternative results' accuracy.

\section{Criteria and tools used}

In this paper we use the positive tensile stress convention and principal stresses are ordered as follows: $\sigma_{I} \geq \sigma_{I I} \geq \sigma_{I I I}$. Stress invariants are mean stress, $\sigma_{m}=\frac{1}{3} \operatorname{Tr}(\underline{\underline{\sigma}})$, second and third invariant of shear stress: $J_{2}=\frac{1}{2} \operatorname{Tr}\left(\underline{\underline{s}}^{2}\right), J_{3}=\frac{1}{3} \operatorname{Tr}\left(\underline{\underline{s}}^{3}\right)$. The polynomial invariant are: $I_{I}=\sigma_{I}+\sigma_{I I}+\sigma_{I I I}, I_{I I}=\sigma_{I} \sigma_{I I}+\sigma_{I I} \sigma_{I I I}+\sigma_{I I I} \sigma_{I}$, $I_{I I I}=\sigma_{I} \sigma_{I I} \sigma_{I I I}$. 


\subsection{Some criteria commonly used in geotechnics}

In this paper we compare Mohr-Coulomb Criterion, Drucker-Prager criterion and Matsuoka-Nakai criterion. These are three commonly used criteria in geotechnics. Criterion are expressed with a yield function $f(\underline{\underline{\sigma}})$ and yield surface correspond to $f(\underline{\sigma})=0$.

\subsubsection{Mohr-Coulomb}

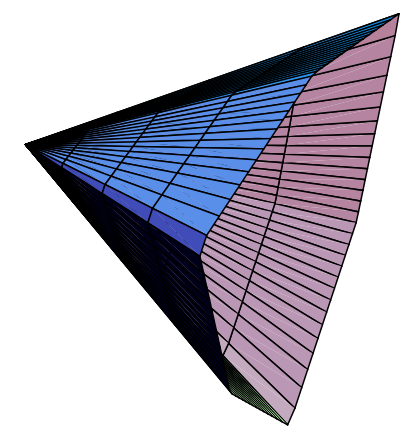

(a) Principal stress space representation

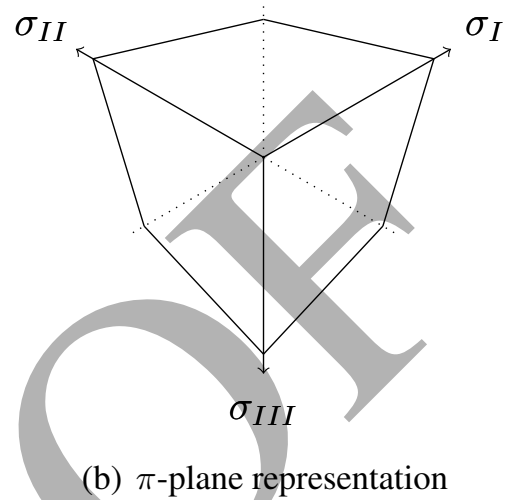

(b) $\pi$-plane representation

Figure 1: Mohr-Coulomb criterion

The Mohr-Coulomb criterion is one of the most commonly used criteria in geotechnics. It's parameters (cohesion $C$ and the internal friction angle $\phi$ ) are easy to deduce from laboratory test and are meaningful for engineers. This criterion is commonly defined with the yield function (1), depending on the principal stresses.

In the principal stress space, its yield surface is a hexagonal conical prism. In the $\pi$-plane its representations are irregular hexagons. With these representations, we can easily see the non-smooth nature of the Mohr-Coulomb criterion.

$$
f(\underline{\underline{\sigma}})=\left(\sigma_{I}-\sigma_{I I I}\right)+\left(\sigma_{I}+\sigma_{I I}\right) \sin \phi-2 C \cos \phi
$$

\subsubsection{Drucker-Prager}

The Drucker-Prager criterion [7] is commonly defined with the yield function (2) depending on the second invariant of the shear stress $J_{2}$ and the mean stress $\sigma_{m}$. The parameter $H$ is the de-cohesion pressure $\left(H=\frac{C}{\tan \phi}\right)$ and $\alpha$ is a frictional parameter.

Its representation in the principal stress space is a circular cone and in the $\pi$-plane a circle. On both representations we can easily see the smooth nature of the criterion.

$$
f(\underline{\underline{\sigma}})=3 \alpha\left(\sigma_{m}-H\right)+\sqrt{J_{2}}
$$




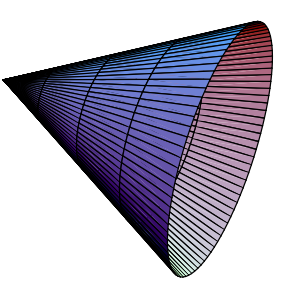

(a) Principal stress space representation

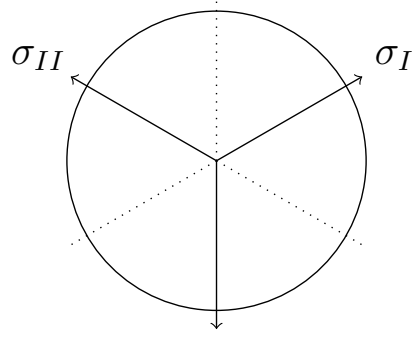

$\sigma_{I I I}$

(b) $\pi$-plane representation

Figure 2: Drucker-Prager Criterion

\subsubsection{Matsuoka-Nakai}
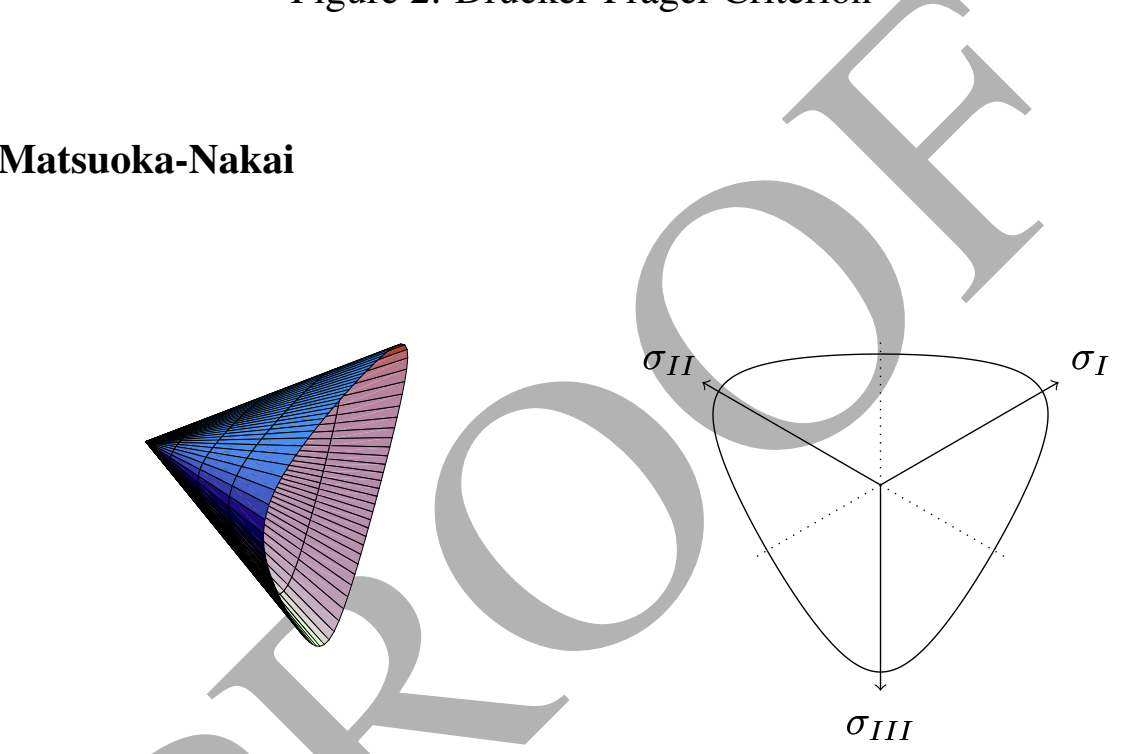

(a) Principal stress space representation

(b) $\pi$-plane representation

Figure 3: Matsuoka-Nakai criterion

The Matsuoka-Nakai criterion [8] is defined with the yield function (Equation (3)) depending on the polynomials invariants $I_{I}, I_{I I}$ and $I_{I I I}$. It's parametrised with the frictional parameter $k_{1}$. The Matsuoka-Nakai criterion was developed for cohesionless materials, but can be adapted to materials with cohesion [9].

On its representations in the principal stress space and $\pi$-plane, we can see that the Matsuoka-Nakai criterion has a non circular smooth shape.

$$
f(\underline{\underline{\sigma}})=k_{1} I_{I I I}-I_{I} I_{I I}
$$

The Matsuoka-Nakai criterion is commonly assumed to be a good smooth approximation to the Mohr-Coulomb criterion. This criterion is even considered closer to 
experimental results than the Mohr-Coulomb criterion[10]. But the closest point projection method [11] or other alternative ones [12], used to compute plastic strain for non-circular smooth criteria are more complex to implement and need more computing time.

\subsection{Some commonly used tools}

Criterion shape has a major importance on plastic strain computation, and on computation time. In this part we present some usable tools to study yield surface shape.

\subsubsection{Extension ratio}

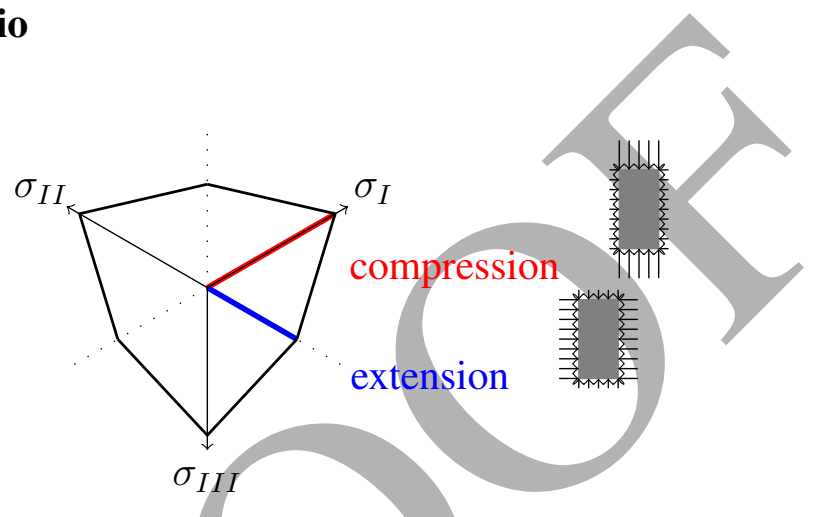

Figure 4: Extension ration measurement on the devitoric shape

The extension ratio is defined in order to describe the difference between the values of $\sqrt{J_{2}}$ in the configuration of extension( $\left.\sigma_{I}=\sigma_{I I} \geq \sigma_{I I I}\right)$ and compression( $\sigma_{I} \geq$ $\sigma_{I I}=\sigma_{I I I}$ ) for the same mean stress. It is described with Equation (4).

$$
L_{s}=\frac{\sqrt{J_{2}}(\text { extension })}{\sqrt{J_{2}}(\text { compression })}=\frac{\left(\sigma_{I}-\sigma_{I I I}\right)(\text { extension })}{\left(\sigma_{I}-\sigma_{I I I}\right)(\text { compression })}
$$

For the Drucker-Prager criterion, which has a circular shape, the extension ratio is $L_{s}=1$. For the Mohr-Coulomb criterion the ratio extension can be described with Equation (5).

$$
L_{s}=\frac{3-\sin \phi}{3+\sin \phi}
$$

\subsubsection{Lode angle and polar decomposition}

The third invariant of the shear stress $J_{3}$ is often replaced by the Lode angle $\theta$. This description of the Lode angle was introduce by Zienkiewics and Pande[13]. (Equation (6)) 


$$
\theta=\frac{1}{3} \arcsin \left(\frac{-3 \sqrt{3}}{2} \frac{J_{3}}{{\sqrt{J_{2}}}^{3}}\right)
$$

The Lode angle can be used to describe a polar decomposition of the yield surface in the $\pi$-plane $\left(\sqrt{J_{2}}, \theta\right)$ (Figure 5). We could also describe $\sqrt{J_{2}}$ with the deviatoric radius $\left(\sigma^{+}=\sqrt{J_{2}} / \theta=\frac{\pi}{6}\right)$ and the shape function $\left(g_{p}(\theta)\right)$ as $\sqrt{J_{2}}=\sigma^{+} g_{p}(\theta)$.

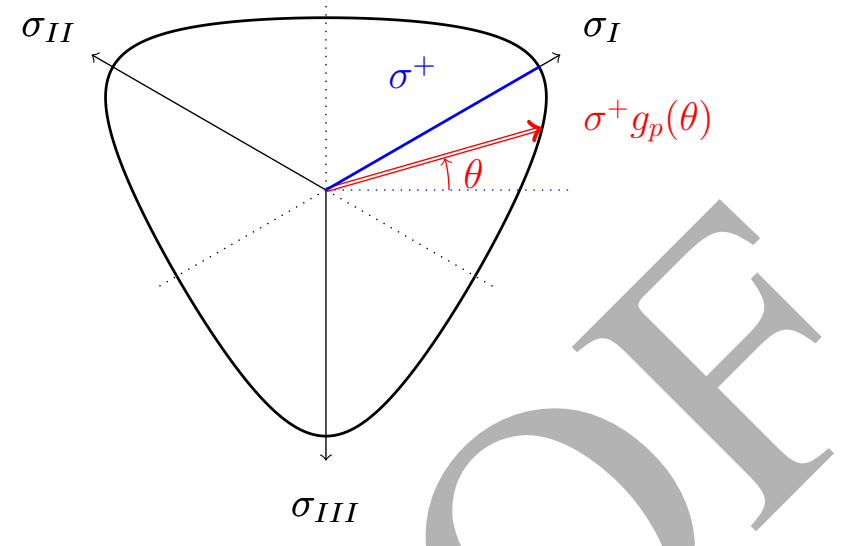

Figure 5: Polar decomposition of the yield surface in the $\pi$-plane

Drucker-Prager The shape function of the Drucker-Prager yield surface is the easiest to describe because of its circular shape. (Equation (7))

$$
g_{p}^{D P}(\theta)=1
$$

Mohr-Coulomb The shape function of Mohr-Coulomb is given by equation (8).

$$
g_{p}^{M C}(\theta)=\frac{3-\sin \phi}{2(\sqrt{3} \cos \theta-\sin \phi \sin \theta)}
$$

Matsuoka-Nakai Matsuoka and Nakai do not directly expose decomposition of the yield surface from their criterion. To decompose the yield surface we have to look at the Maiolino criterion [14] which is equal to the Matsuoka-Nakai if both are fitted onto the Mohr-Coulomb Criterion. Maiolino explains that the Bigoni and Piccolroaz[15] function (Equation(9)) is the numerical solution for the shape function of this criterion with $\beta=0$ and $\gamma=\cos \left(3 \arccos \left(\frac{\sqrt{3}}{2 \sqrt{1-L_{s}+L s^{2}}}\right)\right)$.

$$
g_{p}(\theta)=\frac{\cos \left(\beta \frac{\pi}{6}-\frac{\arccos (-\gamma)}{3}\right)}{\cos \left(\beta \frac{\pi}{6}-\frac{\arccos (-\gamma \sin (3 \theta))}{3}\right)}
$$




\subsection{Correspondence between criteria}

We are looking to substitute the Mohr-Coulomb criterion with other criteria, we have to use the fitted form of these criteria. The criteria parameters have to be linked to the Mohr-Coulomb parameters, cohesion $C$ and the friction angle $\phi$.

\subsubsection{Drucker-Prager fitted to Mohr-Coulomb}

There are currently three ways to fit a Drucker-Prager Criterion to a Mohr-Coulomb criterion. With the compression fit, the two criteria will be equal in a standard compression situation. With the extension fit, the two criteria will be equal of a standard extension situation. And with the inscribed-circle fit, in the $\pi$-plane the DruckerPrager criterion yield surface will correspond to the circle inscribed in the MohrCoulomb hexagon. (Figure 6)

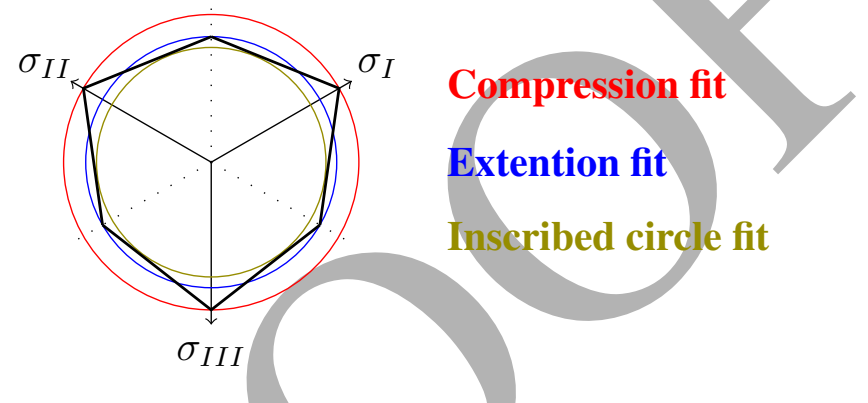

Figure 6: Drucker-Prager fitted onto a Mohr-Coulomb criterion

The values of the Drucker-Prager parameter $\alpha$ for each situation, and the Lode angle values at the matching point $\theta_{c}$ are given in Table 1 . In part 5 we will introduce and compare other Drucker-Prager fitted criteria with a parametric study on $\theta_{c}$.

\begin{tabular}{|l|l|l|}
\hline & $\alpha$ & $\theta_{c}$ \\
\hline Extension fit & $\frac{2 \sin \phi}{\sqrt{3}(3-\sin \phi)}$ & $\frac{\pi}{6}$ \\
\hline Compression fit & $\frac{2 \sin \phi}{\sqrt{3}(3+\sin \phi)}$ & $-\frac{\pi}{6}$ \\
\hline Inscribed circle fit & $\frac{\sin \phi}{\sqrt{3} \sqrt{\left(3+\sin ^{2} \phi\right)}}$ & $-\frac{\sin \phi}{\sqrt{3}}$ \\
\hline
\end{tabular}

Table 1: Parameters for Drucker-Prager fitted to Mohr-Coulomb

\subsubsection{Matsuoka-Nakai fitted to Mohr-Coulomb}

Usually, we only use the Matsuoka-Nakai criterion fitted onto the corners of the MohrCoulomb hexagon. This criterion fit allows correspondence at both extension and 
compression corners of the Mohr-Coulomb hexagon (Figure 2.3.2). To make this fitted form of the criterion we use the parameter $k_{1}$ given by Equation (10).

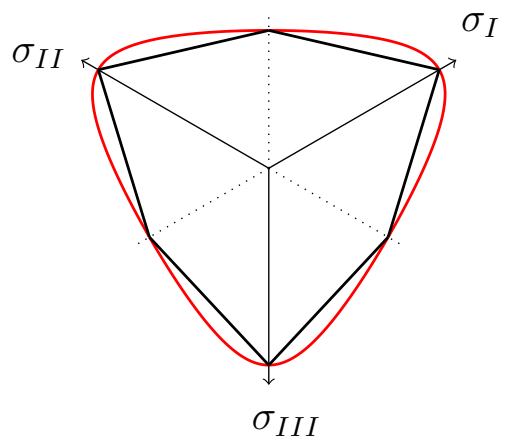

$$
k_{1}=\frac{(3-\sin \phi)(3+\sin \phi)}{(1-\sin \phi)(1+\sin \phi)}
$$

Figure 7: Matsuoka-Nakai criterion fitted to the Mohr-Coulomb criterion

\section{Discrepancy measure and criterion choosing process}

Alternative criteria such as Drucker-Prager can over estimated or under estimated the shear resistance of materials for the same mean stress. Those miss estimated resistance can influence the stress-strain state computation.

Choosing an alternative criterion, we commonly assume that the Matsuoka-Nakai criterion is the best alternative criterion for the Mohr-Coulomb. On the other hand, with the simpler Drucker-Prager criterion, we commonly use the inscribed-circle fitted criterion because it guaranties safety and stability of the material.

In order to improve the choosing process, we use Angle Gap as an innovative measure of discrepancies to compare criteria. And we expose a choosing process based modelling comparison.

\subsection{Apparent friction angle and angle gap measure}

Miss-estimated resistance can be seen and measure on a $\pi$-plane representation of the criteria. A difference between shear radius $\left(\sqrt{J_{2}}\right)$ can be measured, but not simply used and understand. Alternatively, Maiolino and Luong[5] exposed a method for measuring the discrepancies between criteria as a difference between a reference friction angle and an "instant friction angle".

We assume that the cohesion pressure $H$ is the same for every criteria. For any stress state $\left(\sigma_{m}, \sqrt{J_{2}}, \theta\right)$, we can use their equation to give the friction angle parameter of the supposed criterion encountered on this point (Equation (11)). We will call this angle the "resistance angle" $\left(\phi_{r}\right)$, in default situations. 


$$
\phi_{r}(\theta)=\arcsin \frac{\sqrt{3} \sqrt{J_{2}} \cos \theta}{\sqrt{3}\left(H-\sigma_{m}\right)+\sqrt{J_{2}} \sin \theta}
$$

If this stress state also encounters an examined criterion, we can call this angle the "apparent friction angle" $\left(\phi_{a}\right)$ of this criterion. Moreover, if the studied criterion is use as an alternative for an original Mohr-Coulomb criterion described with the internal friction angle $\phi$. The miss estimated shear resistance can be measures as the angle gap between the apparent friction angle $\phi_{a}$ and the original friction angle $\phi$. (Equation (12), figure 8)

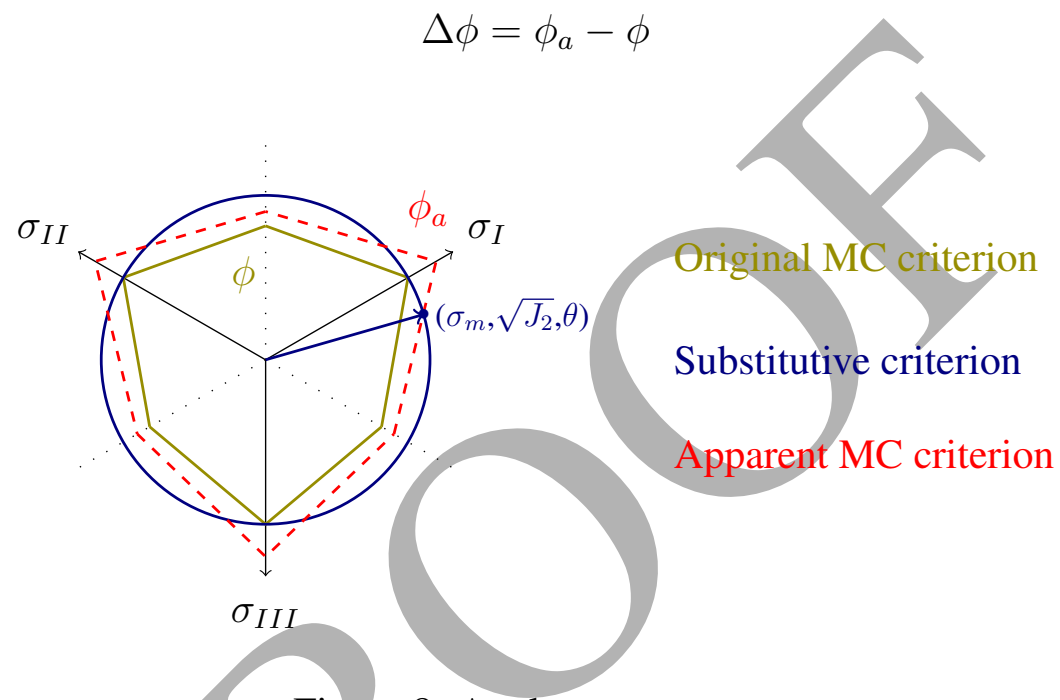

Figure 8: Angle gap measure

\subsubsection{Application to the criteria}

Based on Equation (12),(7),(9),(10) and Table (1), we can represent these discrepancies for all values of the Lode angle and for $\phi$ between $0^{\circ}$ and $45^{\circ}$. (Figure 9)

With these graphs we can anticipate bigger discrepancies on models using the compression-fitted Drucker-Prager criterion.

\subsection{Criterion choosing process}

We based our study on the comparison between the results of two models (2D and 3D). On both models we compute the stress-strain state using each different criteria. We choose to present an associated plastic potential. A simulation with non-associated potential gives similar comparison and conclusion.

On the geometry examined we calculated the final stress-strain state, for every assumption on the criterion. We compared the results to the reference model which uses a Mohr-Coulomb criterion with several meaningful measurements. We used the 


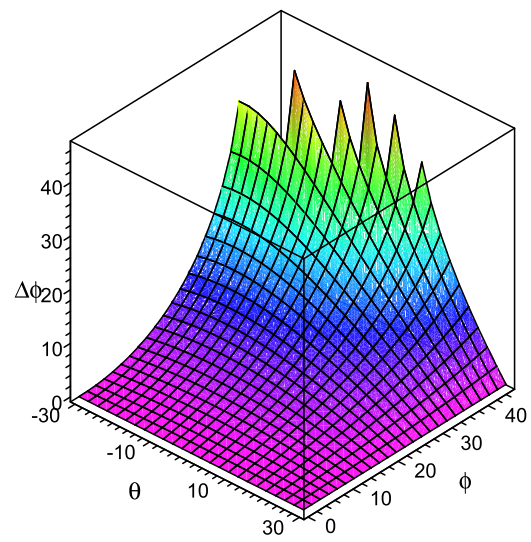

(a) Drucker-Prager compression-fit

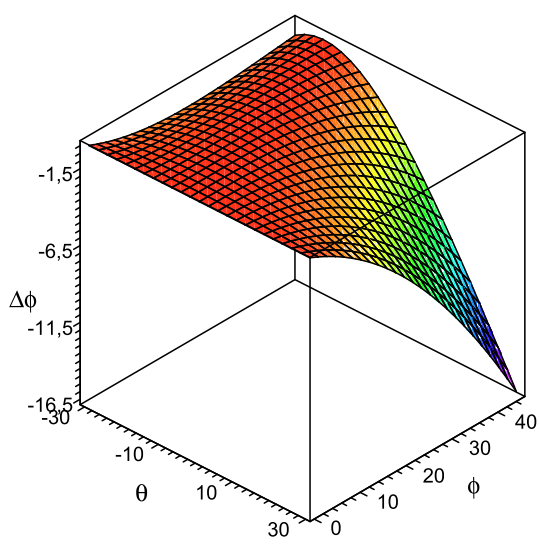

(c) Drucker-Prager inscribed-circle fit

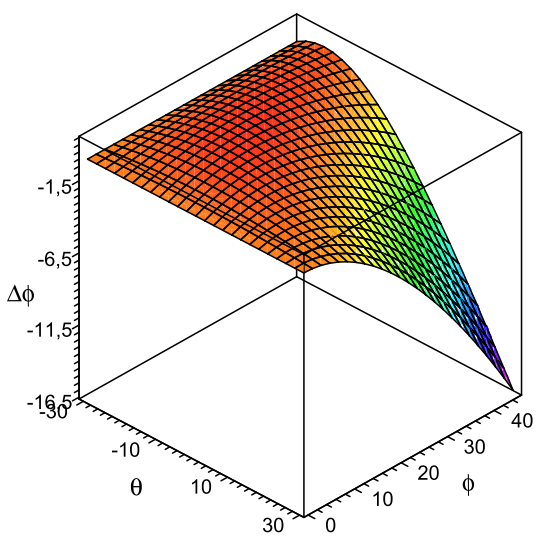

(b) Drucker-Prager extension-fit

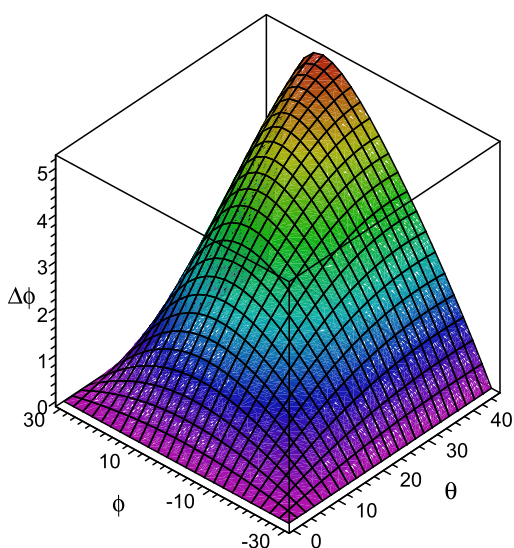

(d) Matsuoka-Nakai

Figure 9: $\Delta \phi$ as a discrepancy measure

following norm for the plasstic strain.

$$
\epsilon_{e f f}=\sqrt{\frac{2}{3} \underline{\underline{\epsilon_{p}}}: \underline{\underline{\epsilon_{p}}}}
$$

We considered only plastic strains greater than $1 E^{-5}$ in order to avoid numerical artefacts due to the finite element interpolation.

During the studies we observed that $\Delta \phi$ as a discrepancy measurement is not really helpful for choosing the best fitted criterion, because of the localization of discrepancies in the structure. To help with this we introduced "weighted discrepancies" in part 4.2.4 as a new measurement of discrepancies defined as the angle gap $\Delta \phi$ multiplied by the norm of the plastic strain $\epsilon_{e f f}$ :

$$
\Delta \phi_{w}=|\Delta \phi| \epsilon_{e f f}
$$


We compared the following measurements:

- Total displacement on a particular meaningful point, frequently the maximal total displacement

- Average plastic strain

- Proportion of plastified zones in the structure

- Total weighted discrepancies

\section{Models and results}

Throughout this study we will not present the results for the Drucker-Prager extension fitted criterion because they are really close to those for the inscribed-circle fitted criterion. Note that this is not a general rule: considering the three distinct Drucker-Prager criteria may be useful for a different structure or with a different value of friction angle.

\subsection{Models}

To illustrate the process we will compute stress-strain states on two railway track models using different criteria. We will compare the results in order to choose which criterion is the best to replace the Mohr-Coulomb criterion for the studies of a railway track studies.

First, we built a simplified 2D geometry for the tracks. Our models use a $50 \mathrm{~cm}$ high layer of ballast under the sleepers. We modelled the sleepers based on a twinblock model. Each block is placed $50 \mathrm{~cm}$ away from the middle of the tracks. Blocks are $60 \mathrm{~cm}$ long and $25 \mathrm{~cm}$ high. At the end of the sleeper we have $50 \mathrm{~cm}$ wide shoulder and a $2 / 3$ downward slope.

For the 3D geometry we use the same dimension for the tracks. The face is extruded to build a quarter of a railway track, $3 \mathrm{~m}$ long, with two and half sleepers. Sleepers are $25 \mathrm{~cm}$ wide and distributed every $60 \mathrm{~cm}$.

We have also examined the results obtained with other models using different track geometry and different sleeper and we obtain the same conclusions.

The ballast parameters are taken from Profillidis' [16] and Suiker's[17] works. Young's modulus $E=110 \mathrm{MPa}$, Poisson's ratio $\nu=0.2$, volumetric mass density $\rho=$ $1.8 \mathrm{t} / \mathrm{m}^{3}$, internal friction angle $\phi=40^{\circ}$. The ballast supposed cohesion-less $(C=$ $0 \mathrm{~Pa}$ ) but we take the value of $5 \mathrm{~Pa}$, insignificant comparing to the loading, to avoid zero division issues in plastic strain computation. The sleeper concrete is modelled with Comsol's standard materials parameters, $E=25 \mathrm{GPa}, \nu=0.33$, and $\rho=$ $2.3 \mathrm{t} / \mathrm{m}^{3}$. 


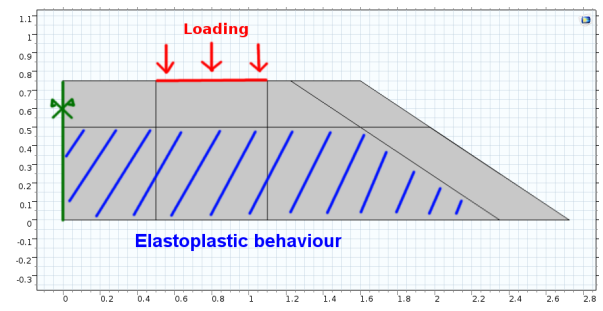

(a)

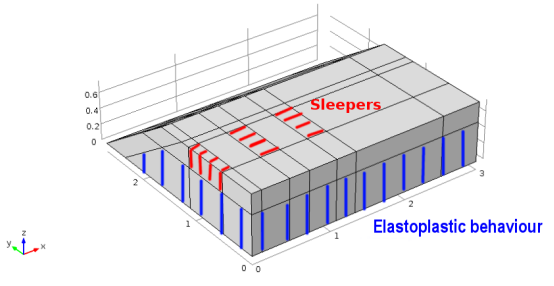

(b)

Figure 10: Used models

The $25 \mathrm{~cm}$ on the top of the geometry is supposed to have elastic behaviour, the under layer is supposed to have elastic-plastic behaviour.

The load is static, monotonic, vertical and uniformly distributed at the top of the sleepers. The axle load is distributed between the sleepers as the typical distribution from V. Profillidis [16] (Figure 11). The maximum load is $0.3 \mathrm{MPa}$ and the total load correspond approximately to the maximum load of $20 \mathrm{t}$ per axle. The $2 \mathrm{D}$ load is also $0.3 \mathrm{MPa}$. Gravity affects the entire structure.

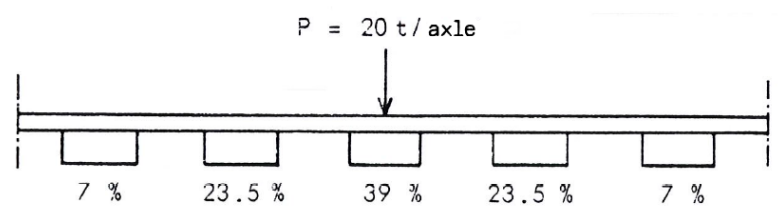

Figure 11: Distribution of the load on the sleeper[16]

We used trapezoidal elements with distribution tools to control meshing. The elements are sized to be smaller near the load in order to limit the quantity of elements and the computation time, but to remain accurate near the load (Figure12). The 3D meshing elements are bigger to improve the convergence of the solution.

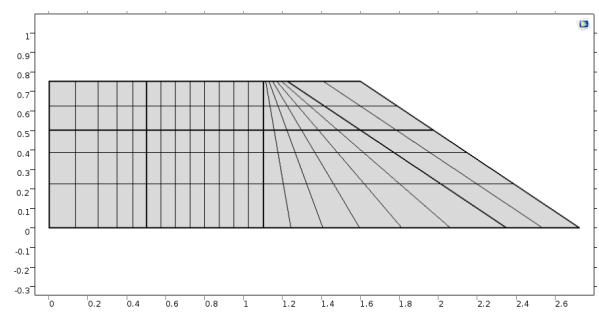

(a)

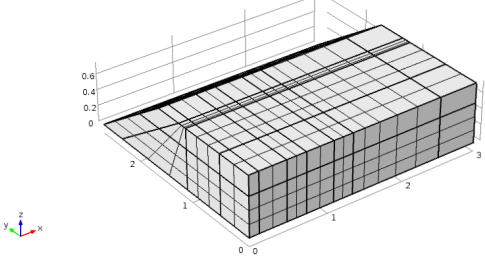

(b)

Figure 12: Trapezoidal mesh used 


\begin{tabular}{|l|l|l|}
\hline \hline 2D model & \multicolumn{2}{|l|}{} \\
\hline Used Criterion & $\begin{array}{l}\text { Maximal total displace- } \\
\text { ment }(\mathrm{mm})\end{array}$ & $\begin{array}{l}\text { Difference with the ref- } \\
\text { erence model }\end{array}$ \\
\hline Mohr-Coulomb criterion & 0.823 & - \\
\hline $\begin{array}{l}\text { Drucker-Prager compression } \\
\text { fitted criterion }\end{array}$ & 0.784 & $-4.7 \%$ \\
\hline $\begin{array}{l}\text { Drucker-Prager Inscribed cir- } \\
\text { cle fitted criterion }\end{array}$ & 0.880 & $+6.9 \%$ \\
\hline Matsuoka-Nakai criterion & 0.794 & $-3.5 \%$ \\
\hline \hline 3D model & \multicolumn{2}{|l|}{} \\
\hline Mohr-Coulomb criterion & 0.392 & - \\
\hline $\begin{array}{l}\text { Drucker-Prager compression } \\
\text { fitted criterion }\end{array}$ & 0.383 & $-2.3 \%$ \\
\hline $\begin{array}{l}\text { Drucker-Prager Inscribed cir- } \\
\text { cle fitted criterion }\end{array}$ & 0.433 & $-1.5 \%$ \\
\hline Matsuoka-Nakai criterion & 0.386 & $+10.5 \%$ \\
\hline
\end{tabular}

Table 2: Maximal total displacement depending on the used criterion

\subsection{D and 3D Results}

In this section we will measure the four parameters named in section 3.2, for each model and each criterion and compare the measurements. We will also explain the choice of some parameters.

\subsubsection{Maximal total displacement}

We measure and compare the maximal total displacement as the meaningful displacement. It is measured under the sleeper. (Table 2)

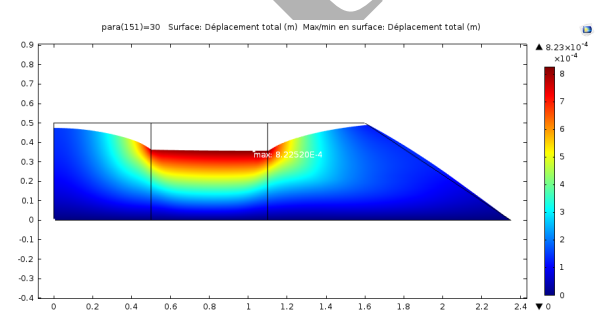

(a)

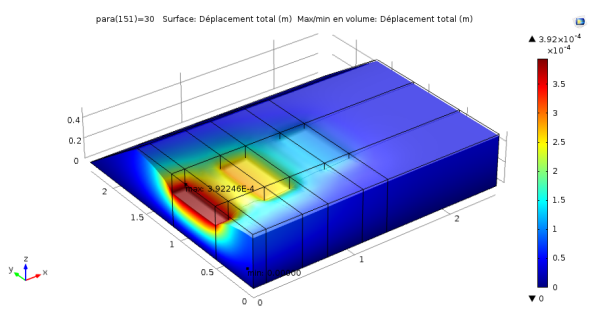

(b)

Figure 13: Total Displacement using the Mohr-Coulomb criterion

As expected, in both 2D and 3D models, the displacement for the inscribed-circle fitted criterion is the biggest: the smallest is for the compression-fitted Drucker-Prager 


\begin{tabular}{|l|l|l|}
\hline Used Criterion & $\begin{array}{l}\text { Average plastic defor- } \\
\text { mation }(\text { def })\end{array}$ & $\begin{array}{l}\text { Difference with the ref- } \\
\text { erence model }\end{array}$ \\
\hline \hline 2D model & \multicolumn{2}{|l|}{} \\
\hline Mohr-Coulomb criterion & $2.01 E^{-4}$ & - \\
\hline $\begin{array}{l}\text { Drucker-Prager compression } \\
\text { fitted criterion }\end{array}$ & $6.43 E^{-5}$ & $-68.0 \%$ \\
\hline $\begin{array}{l}\text { Drucker-Prager Inscribed cir- } \\
\text { cle fitted criterion }\end{array}$ & $4.25 E^{-4}$ & $+111.4 \%$ \\
\hline Matsuoka-Nakai criterion & $1.18 E^{-4}$ & $-41.3 \%$ \\
\hline \hline 3D model & \multicolumn{2}{|l|}{} \\
\hline Mohr-Coulomb criterion & $2.06 E^{-5}$ & - \\
\hline $\begin{array}{l}\text { Drucker-Prager compression } \\
\text { fitted criterion }\end{array}$ & $1.01 E^{-5}$ & $-50.9 \%$ \\
\hline $\begin{array}{l}\text { Drucker-Prager Inscribed cir- } \\
\text { cle fitted criterion }\end{array}$ & $5.94 E^{-4}$ & $+188.3 \%$ \\
\hline Matsuoka-Nakai criterion & $1.36 E^{-4}$ & $-34.0 \%$ \\
\hline
\end{tabular}

Table 3: Average plastic deformation depending on the used criterion

and the closest to the reference with the Matsuoka-Nakai criterion. But we can observe that the result is closer to the reference with the compression-fitted Drucker-Prager than with the inscribed-circle fitted one.

\subsubsection{Average plastic strain}

As explained in our previous work [6], comparing the maximal plastic strain is inappropriate. Because of this, we prefer to observe the average plastic deformation (Table $3)$.

Again, the inscribed circle Drucker-Prager criterion gives the least accurate results. Both compression-fitted Drucker-Prager and Matsuoka-Nakai criteria gives results with comparable accuracy.

\subsubsection{Plastified zones}

We showed the plastified zones on Figure 14. These representations are helpful to see how sensitive the model is to the choice of criterion. We will not attempt to compare these figures qualitatively. Instead, we can measure and compare the proportion of plastified zones in the structure (Table 4).

We can see that the results are relatively close to one other excepted for the inscribedcircle fitted Drucker-Prager Criterion. As with the others comparison parameters, the Matsuoka-Nakai models give the closest result to the reference, and the compressionfitted Drucker-Prager also gives good results. 


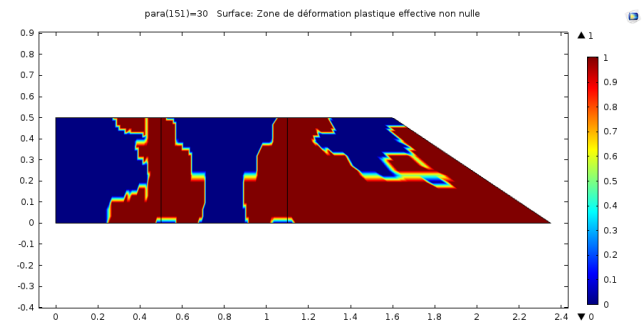

(a)

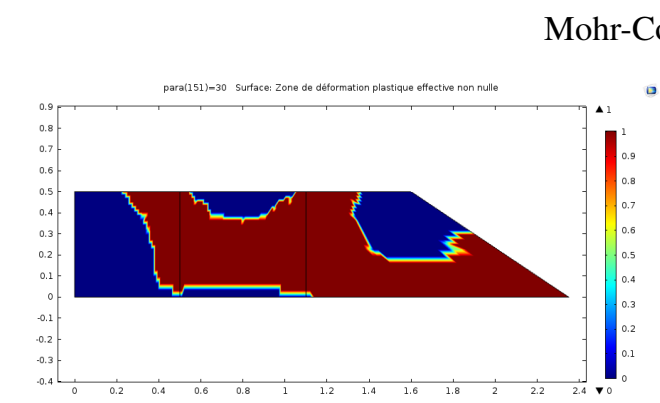

(c)

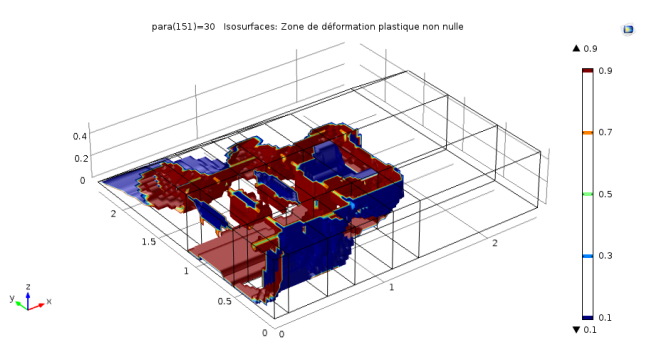

(b)

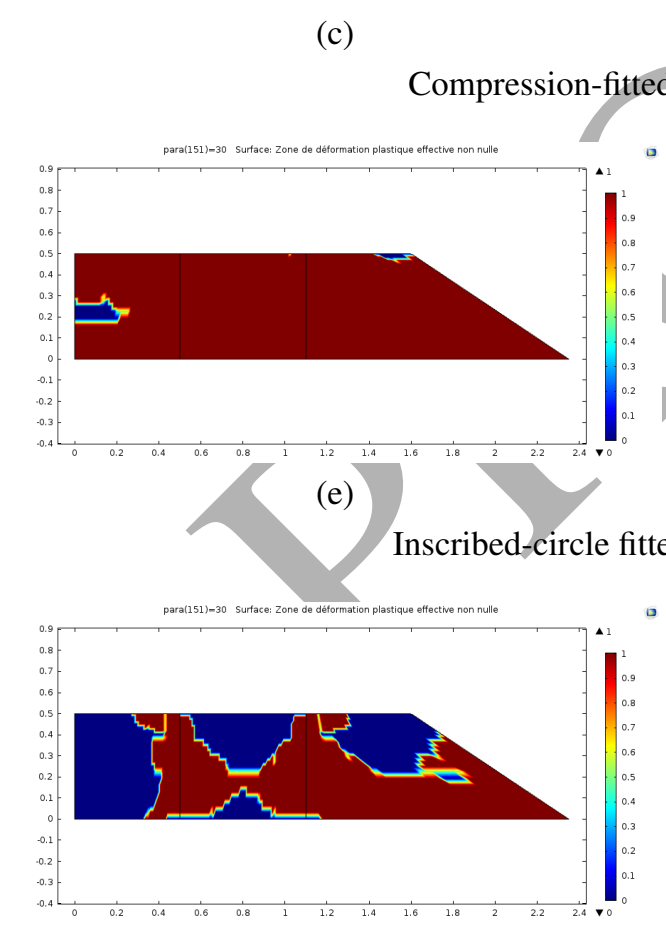

(g) if

s.

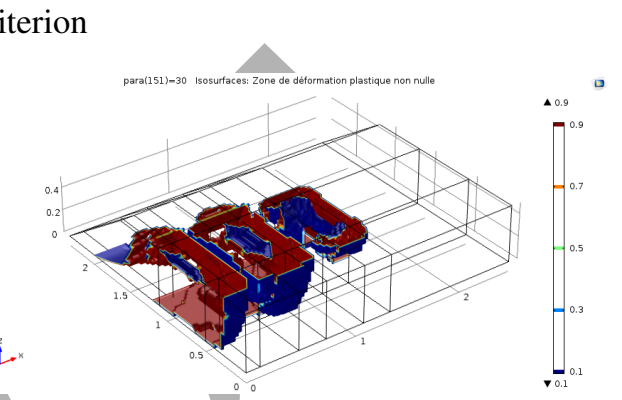

(d)

\section{ker-Prager criterion}

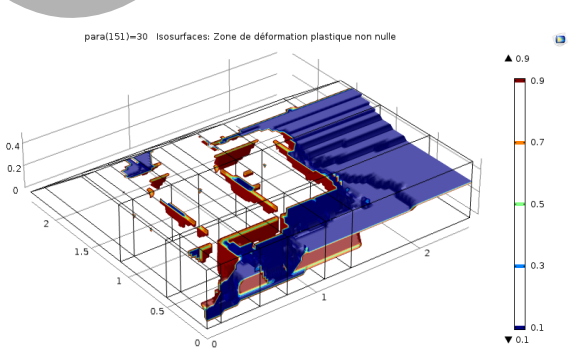

(f)

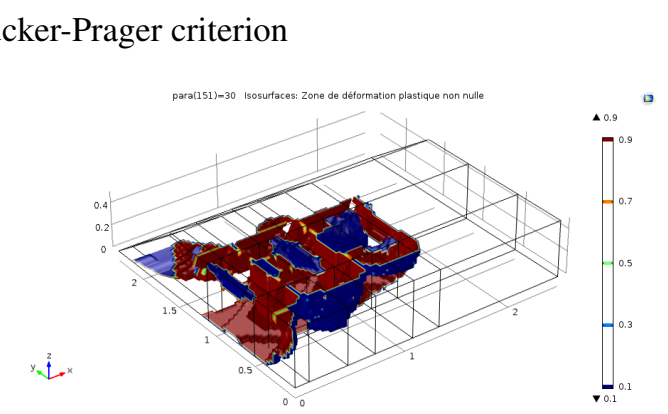

(h)

Matsuoka-Nakai criterion

Figure 14: Plastified zones in the structure 


\begin{tabular}{|l|l|}
\hline Used Criterion & $\begin{array}{l}\text { Proportion of plastified zones in the } \\
\text { structure }\end{array}$ \\
\hline \hline 2D model & $53.1 \%$ \\
\hline Mohr-Coulomb criterion & $59.5 \%$ \\
\hline $\begin{array}{l}\text { Drucker-Prager compression fitted } \\
\text { criterion }\end{array}$ & $98.0 \%$ \\
\hline $\begin{array}{l}\text { Drucker-Prager Inscribed circle fit- } \\
\text { ted criterion }\end{array}$ & $55.7 \%$ \\
\hline Matsuoka-Nakai criterion & $30.7 \%$ \\
\hline \hline 3D model & $17.8 \%$ \\
\hline Mohr-Coulomb criterion & $88.5 \%$ \\
\hline $\begin{array}{l}\text { Drucker-Prager compression fitted } \\
\text { criterion }\end{array}$ & $21.6 \%$ \\
\hline $\begin{array}{l}\text { Drucker-Prager Inscribed circle fit- } \\
\text { ted criterion }\end{array}$ & \\
\hline Matsuoka-Nakai criterion & \\
\hline
\end{tabular}

Table 4: Proportion of plastified zones in the structure depending on the used criterion

More interestingly, it seems that the inscribed-circle fitted criterion gives the worst result at each comparison parameter, whereas it is commonly selected as a "safer" fit. Especially, in measuring the proportion of plastified zones, we can see that almost all the structure is plastified. This is perfectly representative of the problem of the inscribed-circle fitted Drucker-Prager criterion. It has modelled a material that is too weak to represent realistic behaviour of railway ballast.

\subsubsection{Weighted discrepancies}

As we explore the discrepancy measurement as the angle gap [5] (equation 12), we realised that this measure is not meaningful by itself because of the difference of localisation, the positive or negative gap, etc. To avoid this problem, we introduced weighted discrepancies (equation (14)) as a new measurement for discrepancies. We designed this measurement as follows: if a small angle gap is associated with large plastic strain, then the induced discrepancies are much greater. In contrast, even if the angle gap is big, if it is associated with infinitesimal plastic strain, the discrepancies induced are not significant.

Figure 15 show the weighted discrepancies measured in the 2D and 3D models. We can see that the maximal weighted discrepancies are biggest for the compressionfitted Drucker-Prager or Matsuoka-Nakai criteria. But for the same criteria these are restricted to smaller areas. Conversely, for the inscribed-circle fitted Drucker-Prager criterion, the weighted discrepancies are spread extensively.

Finally, we measure and compare the total weighted discrepancies in the structure 


\begin{tabular}{|l|l|}
\hline Used Criterion & $\begin{array}{l}\text { Total weighted discrepancies } \\
\left.\text { (rad.def. } \mathrm{m}^{2} / \text { rad.def. } \mathrm{m}^{3}\right)\end{array}$ \\
\hline \hline 2D model & $1.27 E^{-5}$ \\
\hline $\begin{array}{l}\text { Drucker-Prager compression fitted } \\
\text { criterion }\end{array}$ & $4.40 E^{-5}$ \\
\hline $\begin{array}{l}\text { Drucker-Prager Inscribed circle fit- } \\
\text { ted criterion }\end{array}$ & $8.46 E^{-6}$ \\
\hline Matsuoka-Nakai criterion & $2.25 E^{-6}$ \\
\hline \hline 3D model & $2.51 E^{-5}$ \\
\hline $\begin{array}{l}\text { Drucker-Prager compression fitted } \\
\text { criterion }\end{array}$ & $1.59 E^{-6}$ \\
\hline $\begin{array}{l}\text { Drucker-Prager Inscribed circle fit- } \\
\text { ted criterion }\end{array}$ & \\
\hline Matsuoka-Nakai criterion & \\
\hline
\end{tabular}

Table 5: Total weighted discrepancies depending on the used criterion

in order to compare the different models. (Table 5).

Comparison of this measure lead to the same conclusion, Matsuoka-Nakai give the closest result to the reference, compression-fitted Drucker-Prager criterion gives also good results and inscribed-circle fitted criterion gives the worst results.

\subsubsection{Conclusion of the comparison}

Finally, for both 2D and 3D models we reached the same conclusion for the four comparison parameters. The Matsuoka-Nakai criterion gives the closest result to the reference. And the compression-fitted criterion also gives a good approximation to the result we can get with the Mohr-coulomb criterion. The inscribed-circle DruckerPrager criterion gives the worst result. We realised that this criterion is inappropriate for modelling railway ballast, and the stress strain state we can compute using this behaviour model is not reliable. In addition to this simple conclusion we can deduce that, even though the inscribed-circle fitted Drucker-Prager criterion is commonly selected as a "safer" fit, it can provide the least accurate results, and sometimes should not be selected.

\subsection{Computation time}

The purposes of this study is to evaluate the impact of faster computation criterion. But when we look at the computation times (Table 6), we see that the Matsuoka-Nakai slowed the plastic strain computation, unlike the Drucker-Prager criterion which gave faster computation times. While it is less close to the Mohr-Coulomb criterion, the Drucker-Prager criterion can be useful to provide rapid approximation of material 


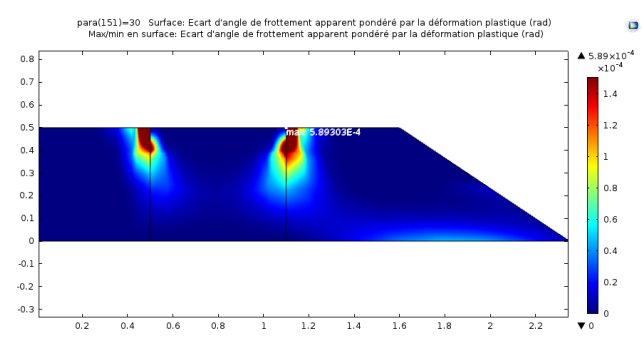

(a)

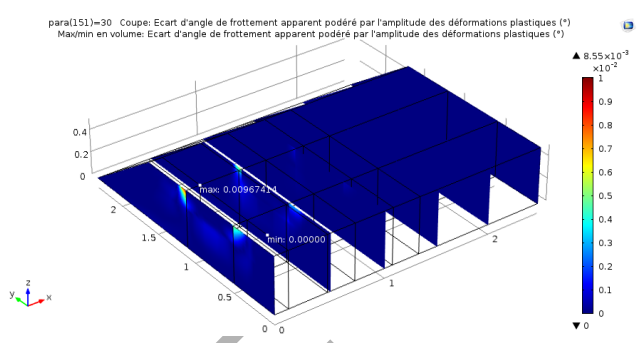

(b)

Compression-fitted Drucker-Prager criterion

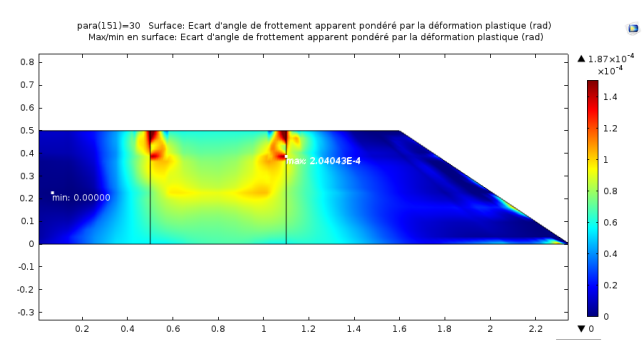

(c)

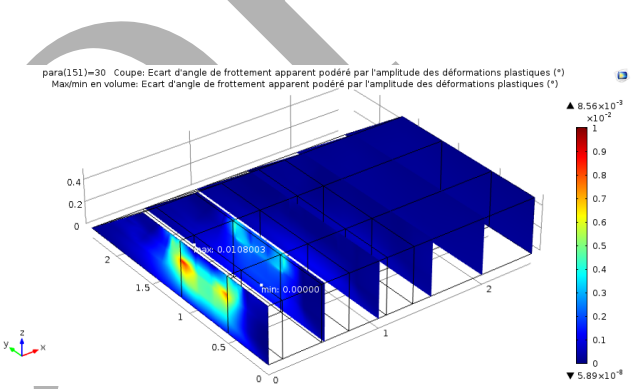

(d)

Inscribed-circle fitted Drucker-Prager criterion

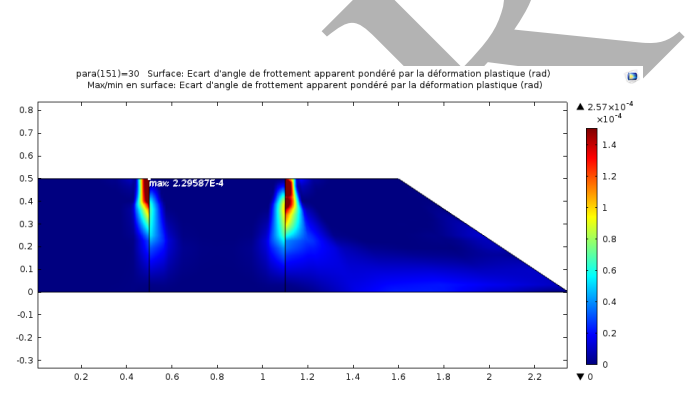

(e)

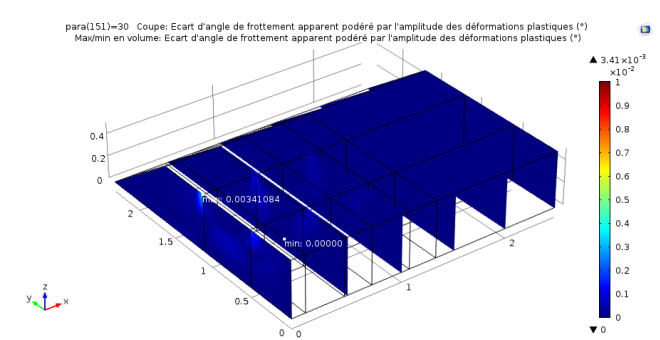

(f)

Matsuoka-Nakai criterion

Figure 15: Measurement of the weighted discrepancies in the structure 
behaviour, if it is wisely selected.

\begin{tabular}{|l|l|l|}
\hline Computing times $(s)$ & 2D Model & 3D Model \\
\hline $\begin{array}{l}\text { Mohr-Coulomb crite- } \\
\text { rion }\end{array}$ & 68 & 250 \\
\hline $\begin{array}{l}\text { Drucker-Prager com- } \\
\text { pression fitted criterion }\end{array}$ & 40 & 190 \\
\hline $\begin{array}{l}\text { Matsuoka-Nakai crite- } \\
\text { rion }\end{array}$ & 75 & 321 \\
\hline
\end{tabular}

Table 6: Computation times depending on the models

\section{Drucker-Prager parametric study}

In the previous section of this paper we showed that the compression-fitted DruckerPrager, surprisingly seems to be the best simple criterion to replace the Mohr-coulomb criterion in our case. Because of the simple shape of the Drucekr-Prager criterion, computation process will lead to the same computation time with any fitting parameter. Based on this assumption we wonder if we can improve model Drucekr-Prager model accuracy with other fitting parameters.

\subsection{Parametrised Drucker-Prager}

In this section we will look at a different way to fit the Drucker-Prager criterion onto a Mohr-Coulomb criterion. We parametrized the Drucker-Prager Criterion in order to link the two criteria at the point of a pre-set: $\theta_{c}$ Lode angle. (Figure 16)

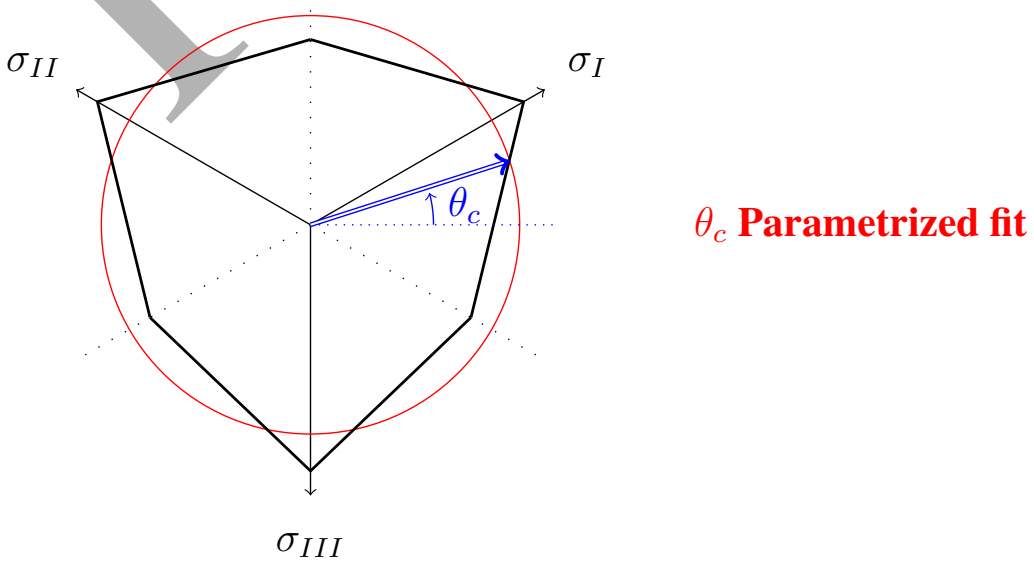

Figure 16: Drucker-Prager fitted onto a Mohr-Coulomb criterion 
(15))

Using equations (2) and (1) we can easily find the expression for $\alpha\left(\theta_{c}\right)$ (Equation

$$
\alpha\left(\theta_{c}\right)=\frac{1}{3} \frac{\sqrt{3} \sin (\phi)}{\sqrt{3} \cos \left(\theta_{c}\right)-\sin (\phi) \sin \left(\theta_{c}\right)}
$$

\subsection{Stress state study}

To help us to choose a fitted criterion and to understand previous conclusion, we study the stress state in the structure. To this end, we computed the Lode angle on the elastic models (Figure 17). This figure shows that almost the entire structure is in a pure compression state, or close to one. When measuring we find the average Lode angle to be $22^{\circ}$ for the $2 \mathrm{D}$ model and $24^{\circ}$ for the $3 \mathrm{D}$ model.

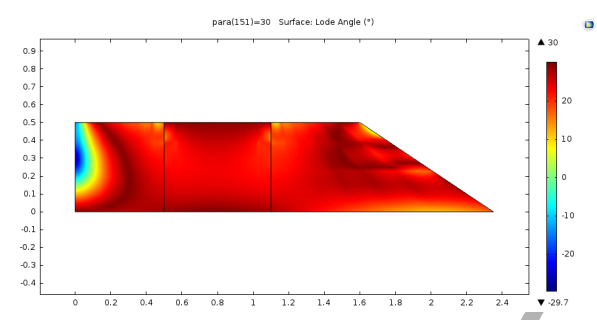

(a)

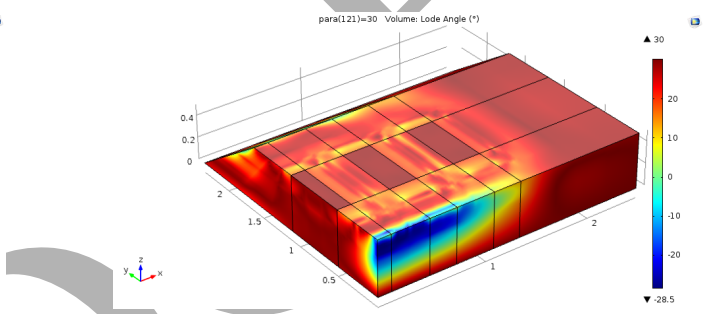

(b)

Figure 17: Lode angle on the elastic models

From this measurement we can deduce that our previous conclusions are logical. For these Lode angles the discrepancies measured as $\Delta \phi$ are $+4^{\circ}$ and $+3.5^{\circ}$ respectively for Matsuoka-Nakai almost, $-11^{\circ}$ and $-10.5^{\circ}$ for Drucker-Prager fitted to the inscribed-circle and $46.5^{\circ}$ and $+5^{\circ}$ for the compression-fitted Drucker-Prager (Figure 18). This means that in an average condition in our structures, in comparison with $\phi=40^{\circ}$ for the ballast, we will over estimate the friction angle by $10 \%$ if we use Matsuoka-Nakai, and by $13 \%$ if we use the compression-fitted Drucker-Prager. But we will underestimate it by more than $25 \%$ if we use the Inscribed-circle fitted Drucker-Prager.

With these measurements we can easily understand our result in the previous section. Even thought the compression-fitted Drucker-Prager criterion generally gives greater discrepancies, in our particular cases they are almost equal to those we obtain with Matsuoka-Nakai. Conversely, the discrepancies are much more significant if we use the inscribed circle fitted Drucker-Prager.

In the same stress condition we can minimise $\Delta \phi$ by choosing $\theta_{c}$ equal to the average stress state Lode angle. In our case we should choose $\theta_{c}=22^{\circ}$ and $\theta_{c}=24^{\circ}$, respectively in our two models. With these criteria, and in an average stress condition, we do not miss estimated the shear resistance of the materials. 


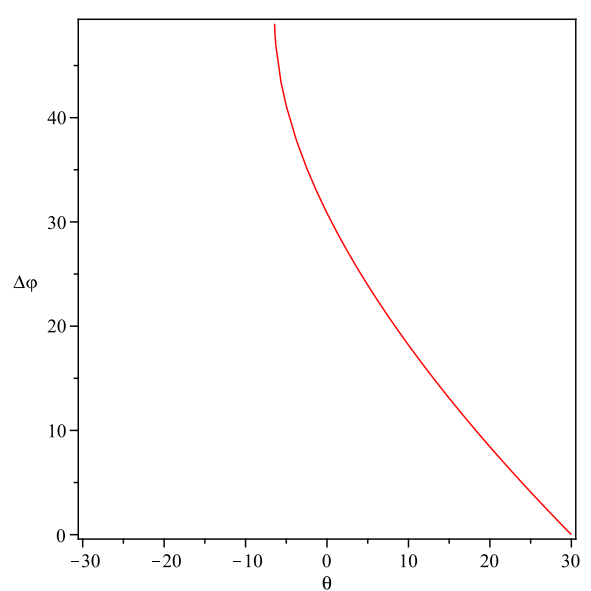

(a) Drucker-Prager compression fit

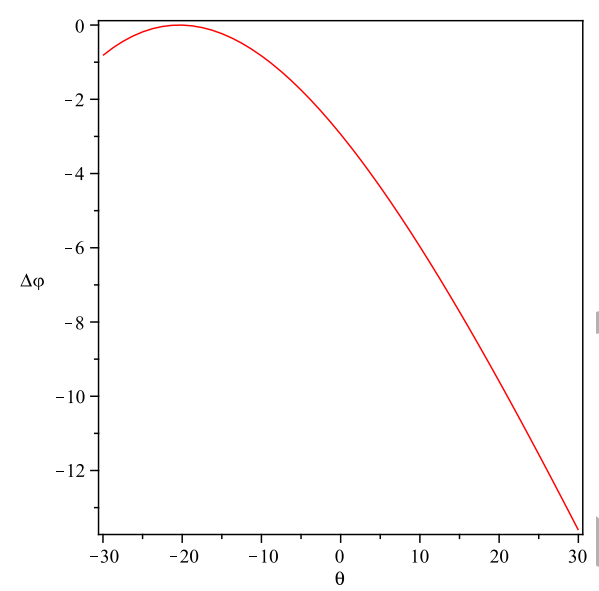

(c) Drucker-Prager inscribed-circle fit

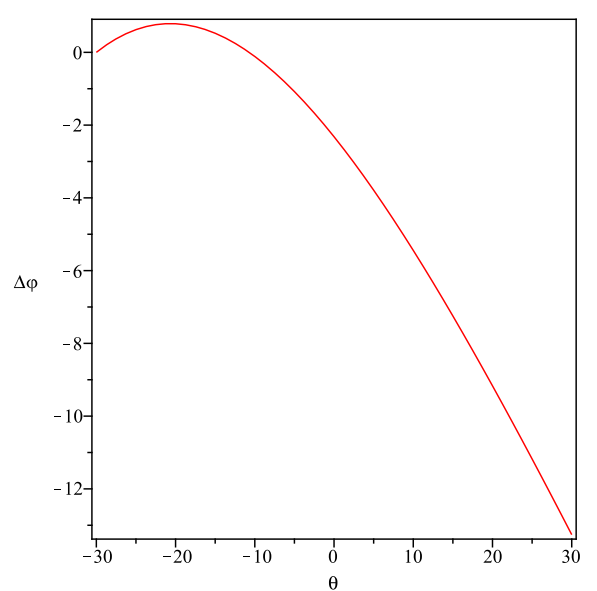

(b) Drucker-Prager extension fit

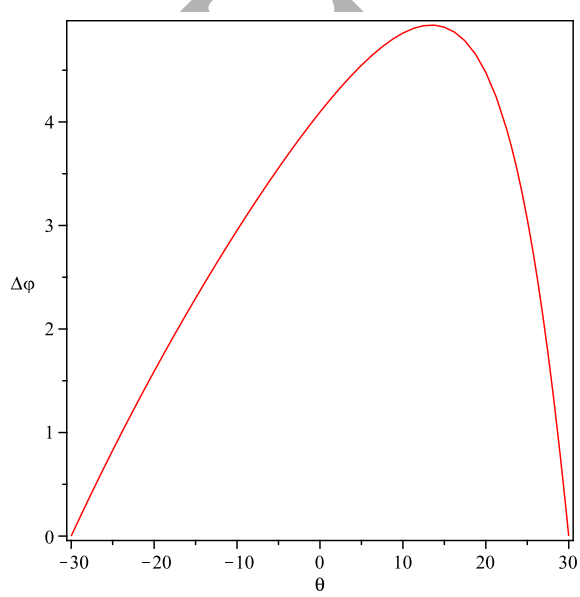

(d) Matsuoka-Nakai

Figure 18: $\Delta \phi$ with a $\phi=40^{\circ}$ Mohr-Coulomb criterion

\subsection{Parametric study}

To confirm this supposition we will do a parametric study and compute the stressstrain state using parametrized Drucker-Prager for each $\theta_{c}$ from $30^{\circ}$ to $15^{\circ}$. Then we will measure the four parameters of the comparison list of section 3.2, for each value of $\theta_{c}$ in 2D and 3D models. The result are presented in Table7. In blue, we note the average Lode angle for each 2D and 3D elastic model and in green we note the best fitted result for each comparison parameter. 


\begin{tabular}{|c|c|c|c|c|}
\hline$\theta_{c}$ & $\begin{array}{c}\text { Meaningful total } \\
\text { displacement }\end{array}$ & $\begin{array}{l}\text { Average plastic } \\
\text { strain }\end{array}$ & $\begin{array}{c}\text { Proportion of } \\
\text { plastified zones in } \\
\text { the structure }\end{array}$ & $\begin{array}{l}\text { Total weighed } \\
\text { discrepancies }\end{array}$ \\
\hline $2 \mathrm{D}$ & 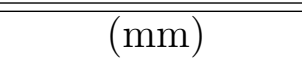 & $\overline{\left(10^{-5} d e f\right)}$ & $\overline{(\overline{(\%)}}$ & 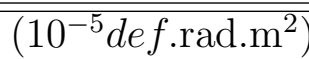 \\
\hline $\mathrm{MC}$ & $\overline{0.823}$ & 20.1 & 53.1 & $\overline{0.00}$ \\
\hline $\mathrm{MN}$ & 0.794 & 11.8 & 55.7 & 0.86 \\
\hline $30^{\circ}$ & 0.784 & 6.43 & 59.5 & 1.27 \\
\hline $29^{\circ}$ & 0.786 & 7.32 & 65.5 & 1.27 \\
\hline $28^{\circ}$ & 0.787 & 8.23 & 68.6 & 1.26 \\
\hline $27^{\circ}$ & 0.789 & 9.18 & 72.9 & 1.24 \\
\hline $26^{\circ}$ & 0.791 & 10.1 & 75.9 & 1.20 \\
\hline $25^{\circ}$ & 0.793 & 11.1 & 77.8 & 1.17 \\
\hline $24^{\circ}$ & 0.795 & 12.1 & 78.1 & 1.14 \\
\hline $23^{\circ}$ & 0.798 & 13.0 & 78.5 & 1.12 \\
\hline 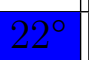 & 0.800 & 14.0 & 80.6 & 1.11 \\
\hline $21^{\circ}$ & 0.802 & 15.0 & 81.7 & 1.11 \\
\hline $20^{\circ}$ & 0.805 & 15.9 & 83.1 & 1.13 \\
\hline $19^{\circ}$ & 0.807 & 16.9 & 83.8 & 1.15 \\
\hline $18^{\circ}$ & 0.810 & 17.8 & 83.9 & 1.19 \\
\hline $17^{\circ}$ & 0.812 & 18.8 & 85.0 & 1.19 \\
\hline $16^{\circ}$ & 0.815 & 19.7 & 85.2 & 1.24 \\
\hline $15^{\circ}$ & 0.818 & 20.7 & 85.9 & 1.37 \\
\hline $3 \mathrm{D}$ & $\overline{(\mathrm{mm})}$ & $\left(10^{-5} \mathrm{def}\right)$ & $(\%)$ & $\overline{(1}\left(10^{-6}\right.$ def.rad.m $\left.{ }^{3}\right)$ \\
\hline "MC & 0.392 & 2.06 & $\begin{array}{l}30.7 \\
\end{array}$ & 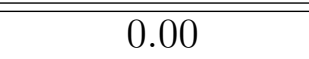 \\
\hline $\mathrm{MN}$ & 0.386 & 1.36 & 21.6 & 1.59 \\
\hline $30^{\circ}$ & 0.385 & 1.02 & 17.9 & 2.35 \\
\hline $29^{\circ}$ & 0.386 & 1.15 & 20.2 & 2.24 \\
\hline $28^{\circ}$ & 0.387 & 1.30 & 23 & 2.14 \\
\hline $27^{\circ}$ & 0.388 & 1.45 & 25.3 & 2.09 \\
\hline $26^{\circ}$ & 0.390 & 1.60 & 27.4 & 2.10 \\
\hline $25^{\circ}$ & 0.391 & 1.76 & 29.4 & 2.19 \\
\hline & 0.392 & 1.92 & 31.1 & 2.37 \\
\hline $23^{\circ}$ & 0.393 & 2.08 & 32.5 & 2.61 \\
\hline $22^{\circ}$ & 0.395 & 2.24 & 33.8 & 2.91 \\
\hline $21^{\circ}$ & 0.396 & 2.39 & 35.1 & 3.27 \\
\hline $20^{\circ}$ & 0.398 & 2.54 & 36.4 & 3.70 \\
\hline $19^{\circ}$ & 0.399 & 2.69 & 37.3 & 4.18 \\
\hline $18^{\circ}$ & 0.401 & 2.84 & 38.4 & 4.72 \\
\hline $17^{\circ}$ & 0.402 & 2.98 & 40.0 & 5.31 \\
\hline $16^{\circ}$ & 0.404 & 3.13 & 41.1 & 5.94 \\
\hline $15^{\circ}$ & 0.405 & 3.26 & 42.8 & 6.59 \\
\hline
\end{tabular}

Green: best fitted results; Blue: average Lode angle in elastic models

Table 7: Result for parametrised Drucker-Prager 
For the $2 \mathrm{D}$ model results, none $\theta_{c}$ parameters gives best fit on several measures. But $\theta_{c}=22^{\circ}$ gives the minimal total weighted discrepancies. Moreover, except for the proportion of the plastified zone, this $\theta_{c}$ parametrised Drucker-Prager gives even. For the $3 \mathrm{D}$ model results, $\theta_{c}=24^{\circ}$ gives the best measurement on two parameters. The two other parameters are also close to the best measurements. Moreover, except for the total weighted discrepancies, this $\theta_{c}$ parametrised Drucker-Prager criterion is a better fitted result to Mohr-Coulomb than Matsuoka-Nakai.

Alternatively and because the Matsuoka-Nakai criterion is considered to be closer to the experimental results, we can also look for the best parametrised Drucker-Prager to fit to the Matsuoka-Nakai. For the 2D model it seems that this is $\theta_{c} \approx 25^{\circ}$ and $\theta_{c} \approx 28^{\circ}$ for the $3 \mathrm{D}$ models.

In any case, using a $\theta_{c}$ parametrised criterion could be useful to improve the fit of a Drucker-Prager criterion onto a Mohr-Coulomb criterion.

We suggest fitting the Drucker-Prager criterion using $\theta_{c}$ equal to the average lode angle measure on an elastic model (rapid pre-computation). Experimentally, and as presented in the examples, those fitted criterion provides better results than those we obtained from the compression-fitted Drucker-Prager on almost every comparison parameters. For most of these, results are even better with parametrised criterion than with Matsuoka-Nakai.

\section{Conclusion}

To efficiently use numerical models to predict long-term behaviour of structures, we need to reduce computation time. For geomaterial modelling, using an alternative criterion is a means of achieving this. Replacing an angular criterion with a smooth criterion is supposed to allow faster computation. But using too complex smooth criterion, even if it provides better result from a physical point of view, could slow down the computation, as we can see with the Matsuoka-Nakai criterion. Instead of this, the compression-fitted Drucker-Prager criterion improves the speed of calculation and gives comparable results to those obtained with the Matsuoka-Nakai criterion.

We can also use a $\theta_{c}$ parametrized Drucker-Prager criterion in order improve the accuracy of the results and find a better fitted criterion. This method seems to be successful using $\theta_{c}$ equal to the average Lode angle measured in the elastic models. With this new criterion we can get betters result than those we obtain with the compressionfitted Drucker-Prager or even the Matsuoka-Nakai Criterion.

Finally, we show that the obvious choice of the inscribed-circle fitted DruckerPrager criterion as an alternative for the Mohr-Coulomb, in order to improve safety could severely over-estimated the plastic strain and reflect weak behaviour compared to that expected. The choice of a Matsuoka-Nakai criterion is also not always appropriate because it slows down the strain computation. Some other Drucker-Prager criteria could be just as accurate and save computation time.

The choice of an alternative criterion must be argued with a specific study for 
each structure and loading considering their particular features. As an almost compressive situation railway tracks should preferably be modelled with a compressionfitted Drucker-Prager criterion as an alternative for the Mohr-Coulomb criterion, or even better, a correctly $\theta_{c}$ parametrised Drucker-Prager criterion. We suggest to precompute stress state and average lode angle on an elastic model. In our case we measure an average stress lode angle of $22^{\circ}$ and $24^{\circ}$ for $2 \mathrm{D}$ and 3D model respectively. Those fitting parameters indeed provide better fitted Drucker-Prager criterion.

While the Drucker-Prager criterion represented a drawback from a physical point of view, it is sufficient to obtain a good approximated model, combined with faster computation and analysis.

\section{References}

[1] A.S. Suiker, R. de Borst, "A numerical model for the cyclic deterioration of railway tracks", International journal for numerical methods in engineering, 57 (4): 441-470, 2003.

[2] I. Einav, "Breakage mechanics-part I: theory", Journal of the Mechanics and Physics of Solids, 55(6): 1274-1297, 2007,a.

[3] I. Einav, "Breakage mechanics-Part II: Modelling granular materials", Journal of the Mechanics and Physics of Solids, 55(6): 1298-1320, 2007,b.

[4] I. Einav, "Fracture propagation in brittle granular matter", in Proceedings of the Royal Society of London A: Mathematical, Physical and Engineering Sciences, Volume 463, pages 3021-3035. The Royal Society, 2007,c.

[5] S. Maiolino, M.P. Luong, "Measuring discrepancies between coulomb and other geotechnical criteria: Drucker-Prager and Matsuoka-Nakai", in 7th Euromech solid mechanics conference, Lisbon, Portugal, pages 09-07, 2009.

[6] T. Badinier, S. Maïolino, "Computation of Ballasted Track Damage: A Comparison of Coulomb, Drucker Prager and Matsuoka Nakai Criteria", in J. Pombo (Editor), The Third International Conference on Railway Technology: Research, Development and Maintenance. Civil-Comp Press, 2016, URL http://dx.doi.org/10.4203/ccp.110.21, paper 21.

[7] D.C. Drucker, W. Prager, "Soil mechanics and plastic analysis or limit design", Quarterly of applied mathematics, 10, 1952.

[8] H. Matsuoka, T. Nakai, "Stress-deformation and strength characteristics of soil under three different principal stresses", in Proc. JSCE, Volume 232, pages 59$70,1974$.

[9] G. Houlsby, "A general failure criterion for frictional and cohesive materials", 26(2): 97-101, 1986. 
[10] T. Nakai, H. Matsuoka, "Shear behaviors of sand and clay under threedimensional stress condition", Soils and Foundations, 23(2): 26-42, jun 1983, ISSN 03851621, URL http: / / ci.nii.ac.jp/naid/110003983402/ en/.

[11] J. Simo, T.J. Hughes, "Computational Inelasticity, volume 7 of Interdisciplinary Applied Mathematics", 1998.

[12] R.I. Borja, K.M. Sama, P.F. Sanz, "On the numerical integration of threeinvariant elastoplastic constitutive models", Computer Methods in Applied Mechanics and Engineering, 192(9): 1227-1258, 2003.

[13] O. Zienkiewicz, G. Pande, "Some useful forms of isotropic yield surfaces for soil and rock mechanics", 1977.

[14] S. Maïolino, "Proposition of a general yield function in geomechanics", Comptes Rendus Mecanique, 333(3): 279-284, 2005.

[15] D. Bigoni, A. Piccolroaz, "Yield criteria for quasibrittle and frictional materials", International journal of solids and structures, 41(11): 2855-2878, 2004.

[16] V. Profillidis, P. Humbert, "Étude en élastoplasticité par la méthode des éléments finis du comportement de la voie ferrée et de sa fondation", Bulletin Liaison $d u$ Laboratoire des Ponts et Chaussées, 141, 1986.

[17] A.S. Suiker, E.T. Selig, R. Frenkel, "Static and cyclic triaxial testing of ballast and subballast", Journal of geotechnical and geoenvironmental engineering, 131 (6): 771-782, 2005.

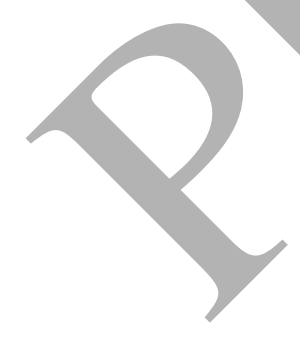

